\title{
Sakarya Üniversitesi Öğrencilerinin Akıllı Telefon Kullanma Düzeyleri ve Yaşam Kalitesi Düzeyleri Arasındaki İlişkinin İncelenmesi
}

\author{
Investigation of The Relationship Between Sakarya University Students' Levels of \\ Smartphone Use and Quality of Life
}

\author{
Erdi Ulutaş ${ }^{1}$, Ali Savaş Çillii ${ }^{2}$, Abdülkadir Aydın ${ }^{3}$, Gürkan Muratdağ ${ }^{4}$, Hasan Çetin Ekerbiçer ${ }^{5}$ \\ ${ }^{1}$ Sağlık Bakanlı̆̆ı Gökçebey İlçe Devlet Hastanesi, Aile Hekimliği, Zonguldak \\ ${ }^{2}$ Sakarya Üniversitesi Tip Fakültesi, Ruh Sağh $\breve{g ̆}$ ve Hastalıkları AD, Sakarya \\ ${ }^{3}$ Sakarya Üniversitesi Eğitim ve Araştırma Hastanesi, Aile Hekimliği, Sakarya. \\ ${ }^{4}$ Sakarya Üniversitesi Tip Fakültesi, Aile Hekimliği AD, Sakarya \\ ${ }^{5}$ Sakarya Üniversitesi Tip Fakültesi, Halk Sağlığı AD, Sakarya \\ Yazıșma Adresi / Correspondence: \\ Gürkan Muratdağ1 \\ Sakarya Üniversitesi Tip Fakültesi, Aile Hekimliği A.D, Sakarya \\ T: +902642953134 E-mail: drgm54@gmail.com
}

Geliş Tarihi / Received : 19.05.2020 Kabul Tarihi / Accepted : 29.06.2020

Orcid :

Erdi Ulutaş, https://orcid.org/0000-0002-8366-9900

Ali Savaş Çilli, https://orcid.org/0000-0003-2479-2949

Abdülkadir Aydın, https://orcid.org/0000-0003-0663-586X

Gürkan Muratdağ1, https://orcid.org/0000-0002-9629-3973

Hasan Çetin Ekerbiçer, https://orcid.org/0000-0003-0064-3893

(Sakarya Tip Dergisi / Sakarya Med J 2020, 10(Özel Say1):24-32) DOI: 10.31832/smj.739137

\footnotetext{
Öz

Amaç Akıllı telefon kullanımındaki hızlı artıș, bağımlılığı ve problemli kullanımı beraberinde getirmektedir. Yapılan araștırmalar akıllı telefon kullanımının sağlığa olumsuz etkisini vurgulamaktayken, yașam kalitesi ile olan ilișkisini tam olarak verememektedir. Bu çalısmada üniversite öğrencilerinde akıllı telefon bağımlılığı ile yașam kalitesi arasındaki ilișkinin araştırılması amaçlanmıștır.

Gereç ve Çalışma Mart 2018 - Mayıs 2018 tarihleri arasında Sakarya Üniversitesinde lisans eğitimi alan 507 üniversite öğrencisi üzerinde gerçekleştirilmiştir. Öğrencilere Yöntemler sosyodemografik özelliklerin sorgulanması amacıyla hazırlanan bir kişisel bilgi formu, akıllı telefon kullanım düzeylerini ölçmek için "Akıllı Telefon Bağımlılı̆̆ Ölçeğı" ile yaşam kalitelerini ölçmek için "WHOQOL-BREF TR Yaşam Kalitesi Ölçeği” uygulandı. Öğrencilerin ölçeklerden aldığı puanlar arasındaki ilișki istatistiksel olarak değerlendirildi.

Bulgular Çalışmaya $267(\% 52,7)$ 'si kadın ve 240 (\%47,3)’ı erkek toplam 507 kişi dahil edilmiștir. Öğrencilerin akıllı telefon kullanım özelliklerine yönelik değerlendirmede kadınların erkeklere göre, aylık harcaması yüksek olanların düşük olanlara göre, düşük yaş grubundakilerin yüksek yaş grubundakilere göre akıllı telefon bağımlılık düzeylerinin daha yüksek olduğu tespit edilmiștir. Akıllı telefon kullanımının yaşam kalitesi üzerine etkisini değerlendirdiğimizde ise bağımlllk düzeyi yüksek olanların yaşam kalitesinin fiziksel, psikolojik ve çevresel sağlık ile sosyal ilişkiler alt gruplarında düşük puan aldığı görülmüștür.

Sonuç Akıllı telefonların günlük hayatı kolaylaștırıcı etkilerinin yanında, așırı kullanımının yașam kaliteleri üzerine negatif yönde etkileri olabileceği görülmektedir. Bu konu üzerine daha kapsamlı ve uzun süreli çalışmaların yapılması gerektiği kanaatindeyiz.

Anahtar Akıllı Telefon Kullanma Düzeyi; Üniversite Öğrencileri; Yaşam Kalitesi

Kelimeler

Abstract

Objective The rapid increase in the use of smartphones brings along addiction and their problematic use. Researches highlighted the negative impact of smartphone use on health, however its relationship with quality of life have not been fully revealed. In this study, it is aimed to investigate the relationship between the quality of life and smart phone addiction among the university students.

Materials The study was conducted between March 2018 and May 2018 on 507 university students studying at Sakarya University. A personal information form which was prepared for the purpose of and Methods questioning sociodemographic characteristics, "Smart Phone Addiction Scale" to measure levels of smartphone use and "WHOQOL-BREF TR Quality of Life Scale" to measure the quality of life were used. The relationship between the scores of the students on each scale was evaluated statistically.

Results The study included $267(52.7 \%)$ females and $240(47.3 \%)$ males with a total of 507 people. In the assessment of students' characteristics of smartphone usage, it was determined that women compared to men, people with higher monthly expenses and people at younger ages had higher levels of smartphone addiction. When we evaluate the effect of smartphone use on quality of life, it was observed that the quality of life of those with higher addiction level had lower scores on physical, psychological, environmental health and social relations subgroups.

Conclusion Besides the daily life-facilitating effects of smartphones, it can be seen that the overuse of smartphones may have negative effects on quality of life. We believe that more comprehensive and long-term studies should be carried out on this subject.

Key words Level of Smartphone Use; University Students; The Quality of Life
} 


\section{GIIRIŞ}

İletişim, yaşamlarımızın merkezi bölümünü oluşturmaktadır. İletişim; var olmak, haberleşmek, paylaşmak, eğlenmek ve mutlu olmak üzere beş temel amaca yönelik olarak gerçekleşmektedir. ${ }^{1}$ Son yıllarda gelişen teknoloji sayesinde, akıllı telefonlar yaşamımızın ayrılmaz bir parçası halini almış ve kişiler arasında yeni bir iletişim ağı oluşturmuştur. Oldukça yakın bir zamanda hayatımızda yer almaya başlayan akıllı telefonlar, toplumsal açıdan dikkat çeken ciddi bir kullanım düzeyine ulaşmıştır. Son 30 yıldır iletişim teknolojilerinde yaşanan bu gelişmeler akıllı telefonların kapasitelerini ve dolayısıyla kullanım alanlarının sınırlarını da genişletmektedir. ${ }^{2}$

Dünya çapında akıllı telefon kullanıcı sayısı 2014 yılında 1,85 milyar kişiye ulaşmıştır. Bu sayının 2020'de ise 2,87 milyar olması beklenmektedir. ${ }^{3}$ Akıllı telefonlar hayatımızda birçok kolaylık sunmakta fakat kullanımlarının dikkat çeken olumsuz etkileri de bulunmaktadır. Akıllı telefon bağımlılığı, akıllı telefon kullanımının kontrol edilemezliği ile ilgili bir olgudur. Bu problemi olan insanlar sosyal, psikolojik ve sağlık sorunlarıyla daha fazla karşılaşırlar. ${ }^{4}$ Özellikle ergen popülasyon (13-19 yaş grubu) akıllı telefon bağımlılığı için yüksek risk grubunu oluşturmaktadırlar. Genellikle akıllı telefonlarına güçlü bir şekilde bağlanmakta ve bir akıllı telefonu ikinci kendileri olarak görmektedirler. Birçok akıllı telefon kullanıcısı bir akıllı telefonu olmadan yaşayamayacaklarını belirtmişlerdir. Gelişimsel olarak, ergenler çeşitli fiziksel ve psikolojik değişiklikler yaşamaktadırlar. Bir yandan ebeveynlerinin hayatlarına ve kimliklerine atıfta bulunurken; diğer yandan ebeveynlerinden bağımsız olmaya, kimliklerini oluşturmaya ve kendileri için bağımsız bir alan yaratmaya çalışmaktadırlar. Bu değişiklikler sırasında, bir akıllı telefon ergenler için vazgeçilmez hale gelmektedir. Aynı zamanda yeni teknolojiyi yakından takip etmekte ve bu tür cihazları yetişkinlerden daha kolay kullanabilmektedirler. ${ }^{4}$

Yaşam kalitesinin, günümüzde tüm bilimler açısından kabul görecek tek bir tanımı bulunmamaktadır. ${ }^{5}$ Ancak tüm tanımlardaki ortak nokta insan faktörü ve onun öznel değerlendirme sistemidir. Genellikle bireyin amaçları, umutları, standartları ve endişeleri ile ilişkilidir. ${ }^{6}$ Dünya Sağlık Örgütü (DSÖ) yaşam kalitesini, "bireyin yaşadığı kültür ve değerler sistemi içinde kendi yaşamını nasıl algıladığı” olarak tanımlamaktadır.

Akıllı telefon kullanımındaki hızlı artış, bağımlılı̆̆ı ve problemli kullanımı beraberinde getirmektedir. Yapılan araştırmalar cep telefonu kullanımının arttığını ve sağlığa olumsuz etkileri olabileceğini vurgulamaktayken, yaşam kalitesine etkisini tam olarak ortaya koyamamaktadır. Bu çalışmada, akıllı telefon kullanım düzeylerinin kişilerin yaşam kalitesi üzerine etkilerinin olup olmadığının belirlenmesi amaçlanmıştır.

\section{GEREÇ ve YÖNTEMLER}

Tanımlayıcı tipte olan çalışmamız Mart 2018 - Mayıs 2018 tarihleri arasında Sakarya Üniversitesinde lisans eğitimi alan 507 üniversite öğrencisi üzerinde gerçekleștirilmiştir. Öğrenciler Sakarya Üniversitesi Mediko Sosyal birimine sağlık hizmeti için başvuranlar içinden seçilerek oluşturulmuştur. Katılımcılara literatürdeki örneklerin ışı̆̆ında hazırlanan sosyodemografik özelliklerin ve alışkanlıkların sorgulandığı kişisel bilgi formu soruları ile birlikte akıllı telefon kullanım düzeylerini ölçmek için "Akıllı Telefon Bağımlılığı Ölçeği” ve yaşam kalitelerini ölçmek için "WHOQOL-BREF TR Yaşam Kalitesi Ölçeği"nnin yer aldığı anket bilgilendirilmiş onamları alındıktan sonra uygulandi.

Tarafımızca öğrencilerin Kişisel bilgi formu, sosyo-demografik bilgileri, bazı kişisel özellikleri, alışkanlıkları, yaşam tarzları ve akıllı telefon kullanma profillerini değerlendiren, açık ve kapalı uçlu toplam 12 adet sorudan oluşmaktadır.

Akıllı Telefon Bağımlılığı Ölçeği, akıllı telefon bağımlılığına ait riski ölçmek için geliştirilen, 10 sorudan oluşan ve altıll Likert dereceleme ile değerlendirilen bir ölçektir. 
Ölçek maddeleri 1'den 6’ya doğru puanlandırılmıştır. Ölçek puanları 10-60 arasında değişmektedir. Testten elde edilen puan arttıkça bağımlılık için riskin arttığı değerlendirilmektedir. Ölçek bir faktörlü olup alt ölçekleri yoktur. Özgün formunun iç tutarlılık ve eş zamanlı geçerliliğinin Cronbach alfa katsayıs $0.938^{\prime}$ dir. $^{7}$

WHOQOL-BREF, Dünya Sağlık Örgütü tarafından geliştirilmiş ve 6 alt boyuttan oluşan WHOQOL-100'ün kısa formudur. WHOQOL-100'den 24 bölümün her biri için birer soru çıkartılarak ve genel sağlık ve yaşam kalitesiyle ilgili iki soru eklenerek oluşturulmuştur. 26 maddeden oluşan ve 5 'li derecelendirme tipine sahip bu ölçek " $1=\mathrm{Hiç} \mathrm{Mem-}$ nun Değilim, 5=Çok Memnunum” şeklinde hazırlanmıştır. Alınan yüksek puan, yüksek yaşam kalitesine işaret etmektedir. Ölçekte; 7 soruyla belirlenen fiziksel sağlık, 6 soruyla belirlenen psikolojik sağlık, 3 soruyla belirlenen sosyal ilişkiler, 8 soruyla belirlenen çevresel sağlık alanı olmak üzere 4 alt boyut bulunur. Ulusal soru olarak eklenen 27. soruya verilen yanitlar dikkate alınarak elde edilen alan, kültüre standardize (KS) olarak tanımlanmaktadır.

Çalışmada toplanan verilerin analizi, istatistiksel yazılım paketi SPSS 23 (Statistical Package for the Social Sciences - IBM ${ }^{\triangleright}$ ) kullanılarak yapıldı. Tanımlayıcı istatistikler, kategorik değişkenler için sayı ve yüzdeler, sayısal değişkenler için ortalama ve standart sapma olarak sunuldu. Sayısal değişkenlerin iki grup arasındaki karşılaştırmalarında bağımsız gruplarda T testi kullanıldı. Ölçek puanları arasındaki ilişkiyi göstermek için Pearson korelasyon analizleri yapıldı. İstatistiksel anlamlılık düzeyini belirlemek için, \%95 güven aralığında ve $\mathrm{p}<0,05$ anlamlı kabul edildi. Bu çalışma için Sakarya Üniversitesi Tip Fakültesi Etik Kurulundan gerekli izin alınmıştır (Tarih:23.02.2018, Say1:71522473/05.01.04/56).

\section{BULGULAR}

Çalışmamıza dâhil edilen 507 öğrenci 18-31 yaş aralığında yer almakla birlikte çoğunluğunu 20-25 yaş aralı̆̆ındaki grup oluşturmaktadır. Öğrencilerin 127’si $(\% 25,05)$ tıp fakültesi, 123’ü (\%24,26) bilgisayar mühendisliği, 136’s1 $(\% 26,82)$ Sağlık Bilimleri Fakültesi’nin Ebelik Bölümü ve 121’i $(\% 23,87)$ Eğitim Fakültesi’nin Temel Eğitim Bölümünde öğrenim görmektedirler. Katılımcıların sosyodemografik özellikleri ve alışkanlıkları Tablo 1' de gösterilmiştir.

\begin{tabular}{|c|c|c|c|}
\hline \multicolumn{4}{|c|}{$\begin{array}{l}\text { Tablo 1. Öğrencilerin sosyodemografik özellikleri ve alışkan- } \\
\text { lıkları }\end{array}$} \\
\hline & & $\mathrm{n}(507)$ & $\%$ \\
\hline \multirow{2}{*}{ Cinsiyet } & Kadın & 267 & 52,70 \\
\hline & Erkek & 240 & 47,30 \\
\hline \multirow{3}{*}{ Yaş } & $\leq 20$ & 124 & 24,40 \\
\hline & $20-25$ & 360 & 71,00 \\
\hline & $\geq 26$ & 23 & 4,60 \\
\hline \multirow{4}{*}{ Okuduğu bölüm } & Tıp Fakültesi & 127 & 25,00 \\
\hline & Bilgisayar Müh. & 123 & 24,30 \\
\hline & Ebelik & 136 & 26,80 \\
\hline & Temel Eğitim Bölümü & 121 & 23,90 \\
\hline \multirow{4}{*}{ Bulunduğu eğitim yılı } & 1. Yil & 132 & 26,00 \\
\hline & 2. Yil & 123 & 24,30 \\
\hline & 3. Yll & 137 & 27,00 \\
\hline & 4. Yil ve üstü & 115 & 22,70 \\
\hline \multirow{2}{*}{$\begin{array}{l}\text { Okuduğu bölümden } \\
\text { memnunluk durumu }\end{array}$} & Evet & 435 & 85,80 \\
\hline & Hayır & 72 & 14,20 \\
\hline \multirow{4}{*}{$\begin{array}{l}\text { Aylık ortalama harca- } \\
\text { ma düzeyi (TL) }\end{array}$} & $\leq 500$ & 25 & 4,90 \\
\hline & $501-1000$ & 148 & 29,20 \\
\hline & $1001-2000$ & 287 & 56,60 \\
\hline & $\geq 2001$ & 47 & 9,30 \\
\hline \multirow{4}{*}{ Yaşadığı yer } & Yurt & 162 & 32,00 \\
\hline & Evde arkadaşlar ile & 230 & 45,30 \\
\hline & Evde yalnız & 85 & 16,80 \\
\hline & Evde aile ile & 30 & 5,90 \\
\hline \multirow{2}{*}{ Düzenli spor yapma } & Hayır & 236 & 67,40 \\
\hline & Evet & 165 & 32,60 \\
\hline \multirow{2}{*}{ Sigara Kullanımı } & Hayır & 397 & 78,30 \\
\hline & Evet & 110 & 21,70 \\
\hline \multirow{2}{*}{$\begin{array}{l}\text { Bedensel hastalık } \\
\text { varlığı }\end{array}$} & Var & 49 & 9,70 \\
\hline & Yok & 458 & 90,30 \\
\hline \multirow{2}{*}{$\begin{array}{l}\text { Psikolojik hastalık } \\
\text { varlığı }\end{array}$} & Var & 25 & 4,90 \\
\hline & yok & 482 & 95,10 \\
\hline \multirow{2}{*}{$\begin{array}{l}\text { Halen kullanılmakta } \\
\text { olan ilaç var mı? }\end{array}$} & Var & 70 & 13,80 \\
\hline & Yok & 437 & 86,20 \\
\hline
\end{tabular}


Akıllı telefon bağımlılık ölçeğinde değerlendirilen maddelerinde cinsiyet değişkenine göre anlamlı farklılıklar olduğu tespit edilmiştir. Değerlendirilen 10 maddenin tamamında kadınların erkeklerden daha yüksek puan ortalamalarına sahip oldukları, istatistiksel anlamlılığın ise sadece beş maddede olduğu görülmüştür (Tablo 2).

\begin{tabular}{|c|c|c|c|c|c|}
\hline & & $\mathrm{n}(507)$ & Puan (Ort-+Std Sapma) & T testi & $\mathrm{p}$ \\
\hline \multirow{2}{*}{$\begin{array}{l}\text { Akıllı telefon kullanmaktan dolayı planladığım işleri } \\
\text { aksatırım }\end{array}$} & Kadın & 267 & $3,42 \pm 1,62$ & $-0,407$ & \multirow{2}{*}{0,173} \\
\hline & Erkek & 240 & $3,36 \pm 1,54$ & $-0,408$ & \\
\hline \multirow{2}{*}{$\begin{array}{l}\text { Akıllı telefonu kullanmaktan dolayı derslerime odaklan- } \\
\text { makta, ödevlerimi yapmakta ve işlerimi tamamlamakta } \\
\text { güçlük çekerim }\end{array}$} & Kadın & 267 & $3,16 \pm 1,71$ & 0,032 & \multirow{2}{*}{0,174} \\
\hline & Erkek & 240 & $3,14 \pm 1,63$ & 0,032 & \\
\hline \multirow{2}{*}{$\begin{array}{l}\text { Akıllı telefon kullanmaktan dolayı el bileğimde veya en- } \\
\text { semde ağrı hissederim }\end{array}$} & Kadın & 267 & $2,98 \pm 1,73$ & $-0,155$ & \multirow{2}{*}{0,447} \\
\hline & Erkek & 240 & $2,95 \pm 1,69$ & $-0,155$ & \\
\hline \multirow{2}{*}{$\begin{array}{l}\text { Akıllı telefonumun yanımda olmamasına tahammül } \\
\text { edemem. }\end{array}$} & Kadın & 267 & $3,31 \pm 1,87$ & $-0,775$ & \multirow{2}{*}{$0,033^{*}$} \\
\hline & Erkek & 240 & $3,19 \pm 1,75$ & $-0,778$ & \\
\hline \multirow{2}{*}{$\begin{array}{l}\text { Akıllı telefonum yanımda olmadığında sabırsız ve sinirli } \\
\text { olurum. }\end{array}$} & Kadın & 267 & $2,90 \pm 1,84$ & $-0,901$ & \multirow{2}{*}{$0,002^{*}$} \\
\hline & Erkek & 240 & $2,76 \pm 1,64$ & $-0,906$ & \\
\hline \multirow{2}{*}{ Kullanmasam da, akıllı telefonum aklımdadır } & Kadın & 267 & $3,18 \pm 1,64$ & 0,597 & \multirow{2}{*}{$0,011^{*}$} \\
\hline & Erkek & 240 & $3,09 \pm 1,82$ & 0,600 & \\
\hline \multirow{2}{*}{$\begin{array}{l}\text { Günlük yaşamımı aksatmasına rağmen akıllı telefonumu } \\
\text { kullanmaktan vazgeçemem }\end{array}$} & Kadın & 267 & $3,12 \pm 1,65$ & 0,100 & \multirow{2}{*}{0,087} \\
\hline & Erkek & 240 & $3,11 \pm 1,76$ & 0,100 & \\
\hline \multirow{2}{*}{$\begin{array}{l}\text { İnsanların twitter veya facebook üzerindeki konuşmalarını } \\
\text { kaçırmamak için sürekli akıllı telefonumu kontrol ederim }\end{array}$} & Kadın & 267 & $2,89 \pm 1,85$ & $-1,466$ & \multirow{2}{*}{$0,005^{*}$} \\
\hline & Erkek & 240 & $2,66 \pm 1,68$ & $-1,474$ & \\
\hline \multirow{2}{*}{$\begin{array}{l}\text { Akıllı telefonumu hedeflediğimden daha uzun süre kul- } \\
\text { lanırım. }\end{array}$} & Kadın & 267 & $3,38 \pm 1,77$ & $-0,356$ & \multirow{2}{*}{$0,008^{*}$} \\
\hline & Erkek & 240 & $3,33 \pm 1,60$ & $-0,358$ & \\
\hline \multirow{2}{*}{$\begin{array}{l}\text { Çevremdeki insanlar akıllı telefonumu çok fazla kul- } \\
\text { landığımı söylerler }\end{array}$} & Kadın & 267 & $2,85 \pm 1,84$ & $-0,897$ & \multirow{2}{*}{0,056} \\
\hline & Erkek & 240 & $2,71 \pm 1,70$ & $-0,901$ & \\
\hline
\end{tabular}


Öğrencilerinin akıllı telefon kullanım özelliklerine yönelik puan ortalamalarının yaş gruplarına göre değerlendirilmesinde ise 20 yaş ve altı olan gruptaki öğrencilerin diğer yaş gruplarıyla karşılaştırıldığında 10 maddenin sekizinde aldıkları puan ortalamaları istatistiksel olarak anlamlı yüksek bulunmuştur. (Tablo 3 ).

\begin{tabular}{|c|c|c|c|c|c|}
\hline & & $\mathrm{n}(507)$ & Puan (Ort-+Std Sapma) & T testi & $\mathrm{p}$ \\
\hline \multirow{3}{*}{$\begin{array}{l}\text { Akıllı telefon kullanmaktan dolayı planladığım işleri } \\
\text { aksatırım. }\end{array}$} & $\leq 20$ & 124 & $3,46 \pm 1,57$ & $-0,885$ & \multirow{3}{*}{0,940} \\
\hline & $20-25$ & 360 & $3,31 \pm 1,58$ & $-0,880$ & \\
\hline & $\geq 26$ & 23 & $2,73 \pm 1,69$ & $-0,734$ & \\
\hline \multirow{3}{*}{$\begin{array}{l}\text { Akıllı telefonu kullanmaktan dolayı derslerime odaklan- } \\
\text { makta, ödevlerimi yapmakta ve işlerimi tamamlamakta } \\
\text { güçlük çekerim. }\end{array}$} & $\leq 20$ & 124 & $3,22 \pm 1,70$ & $-1,164$ & \multirow{3}{*}{$0,007^{\star}$} \\
\hline & $20-25$ & 360 & $3,01 \pm 1,52$ & $-1,231$ & \\
\hline & $\geq 26$ & 23 & $2,73 \pm 1,85$ & $-0,671$ & \\
\hline \multirow{3}{*}{$\begin{array}{l}\text { Akıllı telefon kullanmaktan dolayı el bileğimde veya en- } \\
\text { semde ağrı hissederim. }\end{array}$} & $\leq 20$ & 124 & $3,00 \pm 1,76$ & $-0,57$ & \multirow{3}{*}{$0,014^{*}$} \\
\hline & $20-25$ & 360 & $2,91 \pm 1,52$ & $-0,613$ & \\
\hline & $\geq 26$ & 23 & $2,77 \pm 1,92$ & $-0,115$ & \\
\hline \multirow{3}{*}{$\begin{array}{l}\text { Akıllı telefonumun yanımda olmamasına tahammül } \\
\text { edemem. }\end{array}$} & $\leq 20$ & 124 & $3,35 \pm 1,83$ & $-1,665$ & \multirow{3}{*}{$0,046^{*}$} \\
\hline & $20-25$ & 360 & $3,04 \pm 1,69$ & $-1,728$ & \\
\hline & $\geq 26$ & 23 & $2,68 \pm 1,96$ & $-0,657$ & \\
\hline \multirow{3}{*}{$\begin{array}{l}\text { Akıllı telefonum yanımda olmadığında sabırsız ve sinirli } \\
\text { olurum. }\end{array}$} & $\leq 20$ & 124 & $2,91 \pm 1,79$ & $-1,519$ & \multirow{3}{*}{$0,002^{*}$} \\
\hline & $20-25$ & 360 & $2,64 \pm 1,54$ & $-1,632$ & \\
\hline & $\geq 26$ & 23 & $2,55 \pm 1,81$ & $-0,244$ & \\
\hline \multirow{3}{*}{ Kullanmasam da, akıllı telefonum aklımdadır. } & $\leq 20$ & 124 & $3,18 \pm 1,77$ & $-0,58$ & \multirow{3}{*}{$0,007^{*}$} \\
\hline & $20-25$ & 360 & $3,08 \pm 1,55$ & $-0,618$ & \\
\hline & $\geq 26$ & 23 & $2,59 \pm 1,81$ & $-1,297$ & \\
\hline \multirow{3}{*}{$\begin{array}{l}\text { Günlük yaşamımı aksatmasına rağmen akıllı telefonumu } \\
\text { kullanmaktan vazgeçemem. }\end{array}$} & $\leq 20$ & 124 & $3,17 \pm 1,74$ & $-0,784$ & \multirow{3}{*}{$0,003^{*}$} \\
\hline & $20-25$ & 360 & $3,04 \pm 1,55$ & $-0,828$ & \\
\hline & $\geq 26$ & 23 & $2,55 \pm 1,84$ & $-0,241$ & \\
\hline \multirow{3}{*}{$\begin{array}{l}\text { İnsanların twitter veya facebook üzerindeki konuşmalarını } \\
\text { kaçırmamak için sürekli akıllı telefonumu kontrol ederim. }\end{array}$} & $\leq 20$ & 124 & $2,80 \pm 1,81$ & $-0,301$ & \multirow{3}{*}{0,117} \\
\hline & $20-25$ & 360 & $2,74 \pm 1,66$ & $-0,315$ & \\
\hline & $\geq 26$ & 23 & $2,36 \pm 1,84$ & 0,193 & \\
\hline \multirow{3}{*}{$\begin{array}{l}\text { Akıllı telefonumu hedeflediğimden daha uzun süre kul- } \\
\text { lanırım. }\end{array}$} & $\leq 20$ & 124 & $3,42 \pm 1,71$ & $-0,549$ & \multirow{3}{*}{$0,026^{*}$} \\
\hline & $20-25$ & 360 & $3,33 \pm 1,56$ & $-0,575$ & \\
\hline & $\geq 26$ & 23 & $2,36 \pm 1,71$ & $-0,938$ & \\
\hline \multirow{3}{*}{$\begin{array}{l}\text { Çevremdeki insanlar akıllı telefonumu çok fazla kul- } \\
\text { landığımı söylerler. }\end{array}$} & $\leq 20$ & 124 & $2,84 \pm 1,82$ & $-1,038$ & \multirow{3}{*}{$0,003^{\star}$} \\
\hline & $20-25$ & 360 & $2,65 \pm 1,57$ & $-1,114$ & \\
\hline & $\geq 26$ & 23 & $2,41 \pm 1,96$ & $-0,791$ & \\
\hline
\end{tabular}


Yaşam kalitesi alt paremetrelerinden alınan puanların cinsiyetler arası karşılaştırmasında; öğrencilerin genel sağlık, fiziksel sağlık, çevresel sağlık ve kültüre standardize alt boyutlarından aldıkları puan ortalamaları cinsiyete göre anlamlı farklılıklar göstermektedir. Erkek öğrencilerin ge- nel sağlık, fiziksel sağlık ve kültüre standardize alt boyutlarında yüksek puan ortalamalarına; kadınların ise çevresel sağlık alt boyutunda yüksek puan ortalamasına sahip oldukları tespit edilmiştir (Tablo 4).

\begin{tabular}{|c|c|c|c|c|c|c|}
\hline & & $\mathrm{n}$ & Ortalama Puan & Std. Dev & $\mathrm{t}$ & $\mathrm{p}$ \\
\hline \multirow{2}{*}{ Fiziksel Sağlık } & Kadın & 267 & 15,48 & 2,48 & \multirow{2}{*}{$-0,420$} & \multirow{2}{*}{0,016} \\
\hline & Erkek & 240 & 15,56 & 2,56 & & \\
\hline \multirow{2}{*}{ Psikolojik Sağlık } & Kadın & 267 & 14,04 & 2,42 & \multirow{2}{*}{$-0,996$} & \multirow{2}{*}{0,201} \\
\hline & Erkek & 240 & 14,16 & 2,47 & & \\
\hline \multirow{2}{*}{ Sosyal İlişkiler } & Kadın & 267 & 13,24 & 2,35 & \multirow{2}{*}{$-1,011$} & \multirow{2}{*}{0,011} \\
\hline & Erkek & 240 & 13,96 & 2,39 & & \\
\hline \multirow{2}{*}{ Çevresel Sağlık } & Kadın & 267 & 13,82 & 2,68 & \multirow{2}{*}{1,347} & \multirow{2}{*}{0,019} \\
\hline & Erkek & 240 & 13,64 & 2,27 & & \\
\hline \multirow{2}{*}{$\begin{array}{l}\text { Kültüre Stand- } \\
\operatorname{ardize}(\mathrm{KS})\end{array}$} & Kadın & 267 & 14,94 & 2,41 & \multirow{2}{*}{2,068} & \multirow{2}{*}{0,042} \\
\hline & & 240 & 15,69 & 2,33 & & \\
\hline
\end{tabular}

Çalışmada yer alan öğrencilerin yaşam kalitesi faktörleri ile akıllı telefon kullanımı maddeleri arasındaki ilişkinin korelasyon analizi sonuçları Tablo5’te gösterilmektedir.

\begin{tabular}{|l|c|c|c|c|c|}
\hline Tablo 5. Yaşam Kalitesi Alt Parametreleriyle Akıllı Telefon Kullanımı Maddeleri Arasındaki İlişki & $\begin{array}{c}\text { Fiziksel } \\
\text { Sağlık }\end{array}$ & $\begin{array}{c}\text { Psikolojik } \\
\text { Sağlık }\end{array}$ & $\begin{array}{c}\text { Sosyal } \\
\text { İlişkiler }\end{array}$ & $\begin{array}{c}\text { Kültüre } \\
\text { Standardize }\end{array}$ & $\begin{array}{c}\text { Çevresel } \\
\text { Sağlık }\end{array}$ \\
\hline Akıllı telefon kullanmaktan dolayı planladığım işleri aksatırım &,$- 339^{* *}$ &,$- 100^{*}$ &,$- 427^{* *}$ &,$- 280^{* *}$ &,$- 400^{* *}$ \\
\hline $\begin{array}{l}\text { Akıllı telefonu kullanmaktan dolayı derslerime odaklanmakta, } \\
\text { ödevlerimi yapmakta ve işlerimi tamamlamakta güçlük çekerim }\end{array}$ &,$- 407^{*}$ &,$- 399^{* *}$ &,$- 141^{* *}$ &,$- 411^{* *}$ &,$- 280^{* *}$ \\
\hline $\begin{array}{l}\text { Akıllı telefon kullanmaktan dolayı el bileğimde veya ensemde } \\
\text { ağı hissederim }\end{array}$ &,$- 360^{*}$ &,$- 426^{* *}$ &,$- 372^{* *}$ &,$- 139^{* *}$ &,$- 352^{* *}$ \\
\hline Akıllı telefonumun yanımda olmamasına tahammül edemem &,$- 406^{*}$ &, $663^{* *}$ &, $523^{* *}$ &,$- 399^{* *}$ &,$- 105^{*}$ \\
\hline $\begin{array}{l}\text { Akıllı telefonum yanımda olmadı̆̆ında sabırsı ve sinirli } \\
\text { olurum }\end{array}$ &,$- 360^{*}$ &, $676^{* *}$ &, $653^{* *}$ &, $522^{* *}$ &,$- 349^{* *}$ \\
\hline Kullanmasam da, akıllı telefonum aklımdadır &,$- 392^{*}$ & 1 &, $602^{* *}$ &, $635^{* *}$ &,$- 400^{* *}$ \\
\hline $\begin{array}{l}\text { Günlük yaşamımı aksatmasına rağmen akıllı telefonumu kull- } \\
\text { anmaktan vazgeçemem }\end{array}$ &,$- 422^{*}$ &, $602^{* *}$ &, $685^{* *}$ &, $551^{* *}$ &,$- 393^{*}$ \\
\hline $\begin{array}{l}\text { İnsanların twitter veya facebook üzerindeki konuşmalarını } \\
\text { kaçırmamak için sürekli akıllı telefonumu kontrol ederim }\end{array}$ &,$- 389^{*}$ &, $638^{* *}$ &, $800^{* *}$ &, $685^{* *}$ & $-0,327$ \\
\hline Akıllı telefonumu hedeflediğimden daha uzun süre kullanırım &,$- 419^{*}$ &, $551^{* *}$ &, $685^{* *}$ &, $680^{* *}$ & $-0,385$ \\
\hline $\begin{array}{l}\text { Çevremdeki insanlar akıllı telefonumu çok fazla kullandığımı } \\
\text { söylerler }\end{array}$ &,$-- 385^{*}$ &, $669^{* *}$ &, $712^{* *}$ &, $522^{* *}$ & $-0,341$ \\
\hline p<0,05 anlamlılık, Pearson Korelasyon Analizi, & & \\
\hline
\end{tabular}




\section{TARTIŞMA ve SONUÇ}

Akıllı telefonlar insan yaşamına sağladığı kolaylıkların artması ile birlikte gündelik yaşamın ayrılmaz bir parçası olmuştur. Akıllı telefonlar bilinçli olarak kullanıldığında kullanıcısına amacı doğrultusunda birçok kolaylık sağlayan önemli teknolojik buluşlardan biridir. Bunun yanı sıra, akıllı telefonların amacı dışında aşırı derecede kullanımı kullanıcının biyolojik, fizyolojik, psikolojik ve sosyal gelişimini olumsuz yönde etkileyebilmektedir. Özellikle genç yaştaki kullanıcılar başta olmak üzere, akıllı telefonların gereğinden fazla kullanılması akıllı telefon bağımlıllğı gibi olumsuz sonuçlara da neden olabilmektedir. ${ }^{8}$

Yapılan araştırmalar cep telefonu kullanımının arttığını ve sağlığa olumsuz etkisini vurgulamaktayken, yaşam kalitesi ile olan ilişkisini tam olarak verememektedir. Bu çalışmada, üniversitesi öğrencilerinin akıllı telefon kullanma düzeyi ve yaşam kalitesi arasındaki ilişki incelenmeye çalışılmış ve bu iki değişken arasındaki ilişkinin ortaya konması amaçlanmıştır.

Çalışmamızda öğrencilerin yaşam kalitesi ölçeği alt boyutlarından fiziksel sağlık, sosyal sağlık, çevresel sağlık ve kültüre standardize alanları cinsiyete göre anlamlı bir farklılık göstermektedir. Bu alt boyutlarda erkek öğrencilerin yaşam kaliteleri kadın öğrencilere göre daha yüksektir. Bu sonuç kız öğrencilerde erkek öğrencilerden farklı olarak bu alanlar üzerinde etkili olabilecek biyolojik, sosyal, kültürel, ekonomik koşul ve/veya durumların araştırılması gereğini düşündürmektedir. Vuillemin ve ark'nın yapmış oldukları çalışmada erkeklerde fiziksel aktivite düzeyi ile SF-36'nın fiziksel skorları arasında pozitif yönde ve anlamlı bir ilişki bulunmuştur. ${ }^{9}$ Çalışmanın, çevresel koşullar, psikolojik sağlık ve sosyal ilişkiler arasında olumlu yönde ve anlamlı bir ilişkinin varlığı bulgusuna paralel olarak Cankovic ve ark.'nın yaptıkları çalışmada, çevre ile toplam yaşam kalitesi arasında olumlu bir ilişki bulmuşlardır. ${ }^{10}$ Fiziksel koşulların yeterliliği, güvenli bir ortam, yeterli finansal koşullar, boş zaman değerlendirme olanakları, sağlık hizmetlerinden yararlanabilme, ulaşım olanakları gibi çevresel boyut koşullarının kaliteli yaşam algısıyla daha fazla ilgili olduğu görülmektedir.

Çalışmamızla benzer sonuçlar saptayan bir çalışmada, yaşam kalitesinin fiziksel sağlık alanı cinsiyete göre istatiksel açıdan anlamlı bir fark göstermektedir. Erkek öğrencilerin bedensel alan ortalamaları kız öğrencilere göre daha yüksektir. Erkek öğrencilerin fiziksel sağlık ortalamaları kız öğrencilere göre daha yüksektir. Bu bulgu Türkiye'de yapılmış birçok çalışmayla uyumludur. ${ }^{11-14}$ Aldinç ve ark. (2004) çalışmasında ise cinsiyete göre bedensel alan ortalamaları açısından fark bulunmamıştır. ${ }^{12}$ Ancak Türkiyede yapılmış çalışmalarda bu konuda birbirinden farklı sonuçlar bulunduğu görülmektedir. Bunun nedeni yaşam kalitesi ölçeklerinin genelde hasta, yaşlı, özel bir meslek grubunda ya da tedavi sonrası tedavinin etkinliğini belirleyebilmek amacıyla kullanılması olabilir.

Günümüzde ebeveynler çocuklarının fiziksel sağlığı veya okul başarısı üzerinde durdukları kadar teknoloji kullanımının taşıdığı riskler hakkında duyarlı değillerdir. Bu yüzden erken yaştan itibaren çocuklarda problemli akıllı telefon kullanımı ve bağımlılık sorunları ortaya çıkmaktadır. Çalışmamız verileri 20 yaş ve altı öğrenci grubundakilerin akıllı telefon kullanma düzeylerinin diğer yaş gruplarındaki öğrencilere göre daha yüksek olduğunu göstermektedir. Bu bulgu özellikle gençlerin akıllı telefon kullanma konusundaki isteklerinin nasıl da bağımlılığa dönüştüğünü göstermektedir. Yaş düştükçe akıllı telefonlara olan bağımlılık artmaktadır. Kuyucu 620 üniversite öğrencisi üzerinde yaptığ çalışmasında üniversite öğrencilerinin akıllı telefon bağımlılık düzeylerini araştırmıştır. Çalışma sonucunda 21-23 yaş grubundakilerin 27 yaş ve üzerindekilere göre daha fazla cep telefonlarına olumlu anlam yükledikleri görülmüştür. ${ }^{15}$

Çalışmamızda 20-25 yaş aralığındaki öğrencilerin yaşam kalitesi ölçeği alt boyutlarından aldığı ortalama puanlarının diğer yaş gruplarından daha yüksek olduğu saptandı. Bütün alt boyutlarda araştırma grubunun yaş değiş̧keni ile 
yaşam kalitesi faktörleri arasındaki ilişki incelendiğinde; sadece psikolojik sağlık ve sosyal ilişkiler alt boyutlarında istatistiksel olarak anlamlı bir fark bulunurken, diğer alt boyutlarda istatistiksel olarak anlamlı bir fark tespit edilememiştir. Karşılaştırma yapılan çalışmalar genelde yaşlılar üzerinde yapılmış olduğundan ve bu çalışmanın yaş ortalaması nispeten daha düşük, dolayısıyla daha genç ve aktif çalışan bir grupta yapılmış olduğundan yaşam kalitesi diğer araştırmalardan daha iyi bulunmuş olabilir. Gerçekten de yaş faktörü, alan puanlarını etkileyen değişkenlerden biri olarak literatürde yer almaktadır. ${ }^{13,16}$

Sakarya Üniversitesi 2017 yllı verilerine göre toplamda 94375 öğrenciye sahip olup bunların 51514 (\%54,58) kadarını lisans öğrencileri oluşturmaktadır. Üniversite’nin okuyan kız/erkek oranı 40/60'dır. Toplamda bünyesinde 19 fakülte, 14 yüksekokul, 4 enstitü barındıran Sakarya Üniversitesinin tüm öğrencileri çalışmaya dahil edilemedi ve tüm eğitim birimlerine ulaşılamadı. Bu durum çalışmamızın kısıtlılık faktörüdür.

Sonuç olarak; çalışmamızda farklı fakültelerde öğrenim gören toplam 507 üniversite öğrencisine akıllı telefon kullanım düzeylerini ve yaşam kalitelerini değerlendiren ölçekler uygulandı. Akıllı telefon bağımlılık skorları yüksek saptanan öğrencilerin yaşam kalitesi skorlarının, akıllı telefon bağımlılık skoru daha düşük saptanan öğrencilere göre daha düşük olduğu saptandı. Bu bağlamda akıllı telefon kullanımı düzeyi ile yaşam kalitesi arasında negatif korelasyon olabileceği düşünüldü. Yapılan çalışmaların büyük kısmında kadın cinsiyet veya düşük yaş grubu akıllı telefon bağımlılığının daha yoğun görüldüğü gruplar olarak değerlendirilse de literatürde bu değişkenlerin akıllı telefon bağımlılığı ile ilişkilerinin olmadığı yönünde değerlendirmede bulunan çalışmalar da mevcuttur. Bizim verilerimiz de; kadınlarda, düşük yaş gruplarında ve ekonomik düzeyi yüksek olanlarda akıllı telefon bağımlılığının daha yüksek olduğunu desteklemektedir.

Yaşam kalitesini etkileyen birçok faktör olduğu bilinmek- tedir. Çalışmamız verileri bu faktörlerden birinin de problemli akıllı telefon kullanımı olduğunu göstermektedir. Literatürde akıllı telefon kullanımının kişilerin akademik başarıları, kaygı durumları ve bağımlılık seviyeleri üzerine etkilerinin değerlendirildiği birçok çalışma bulunmaktadır. Fakat direk yaşam kalitesi üzerine etkisinin değerlendirildiği yeterli çalışma bulunmamaktadır. Bu bağlamda çalışmamız sonuçları bu alandaki eksikliğin kapatılmasına katkı sağlayacaktır.

Akıllı telefon kullanımı günümüzde oldukça yaygınlaşmakta ve kullanmaya başlama yaşı giderek düşmektedir. Yararlı etkilerinin yanında olası zararlı etkilerinin de ortaya konması özellikle hitap ettiği yaş grupları nedeniyle oldukça önemlidir. Bu olası etkilerin tespiti ve bu etkilere karşı alınması gerek önlemler değerlendirilmeli, gelecek nesillerde problemli akıllı telefon kullanımının önüne geçilmelidir. Bu bağlamda akıllı telefon bağımlılığının negatif etkileri ve alınması gereken önlemlere ışık tutabilecek daha kapsamlı çalışmalara ihtiyaç olduğu kanısındayız.

\section{Etik Kurul Onayı}

Bu çalışma için Sakarya Üniversitesi Tıp Fakültesi Etik Kurulundan gerekli izin alınmıştır (Tarih:23.02.2018, Say1:71522473/05.01.04/56). 
Sakarya Tıp Dergisi 2020;10(Özel Sayı):24-32

\section{Kaynaklar}

1. . Kaypakoğlu S. Kișilerarası Illetișim: Cinsiyet Farkllikkları, Güç ve Çatıșma. 1. Baskı. İstanbul: Derin Yayınlari; 2008. s:123-52.

2. Kahyaoğlu S, Kurt S, Uzal O, Ozdilek S. Effects of smartphone addiction level on social and educational life in health sciences students. Euras J Fam Med. 2016;5(1):13-9.

3. https://www.statista.com/statistics/263441/global-smartphone-shipmentsforecast/, Erișim tarihi: 13.08 .2018

4. Young KS. Cognitive behavior therapy with internet addicts: Treatment outcomes and implications. Cyberpsychol Behav. 2007;10(5):671-9.

5. Bilir N, Özcebe H, Vazioğlu SA, Aslan D, Subașı N, Telatar TG. Van ilinde 15 yaș üzeri erkeklerde SF-36 ile yașam kalitesinin değerlendirilmesi. Türkiye Klinikleri Journal of Medical Sciences. 2005;25(5):663-8.

6. Torlak SE, Yavuzçehre PS. Denizli kent yoksullarının yaşam kalitesi üzerine bir inceleme. Çağdaş Yerel Yönetimler. 2008;17(2):23-44.

7. Kwon M, Lee JY, Won WY, Park JW, Min JA, Hahn C, Gu X, Choi JH, Kim DJ. Development and validation of a smartphone addiction scale (SAS). PLoS One. 2013;8(2):1-7.

8. Pearson C, Hussain Z. Smartphone addiction and associated psychological factors. ADDICTA: The Turkish Journal of Addictions. 20163(2):193-207.

9. Vuillemin A, Boini S, Bertrais S, Tessier S, Oppert JM, Hercberg S, Guillemin F, Briançon S. Leisure time physical activity and health related quality of life. Prev Med. 2005;41(2):562-9.
10. Cankovic S, Ac-Nikolic E, Susnjevic S, Cankovic D, Radic I, Harhaji S. Environment and quality of life of older people. Healthmed. 2012;6(5):1815-20.

11. Kaya M. (2003). Ankara'da 112 Acil Yardım Hizmetlerinde Çalı̧san Sağlık Personelinin Öznel Yaşam Kalitelerinin Değerlendirilmesi. AÜ Sağlk Bilimleri Enstitüsü, Yüksek Lisans Tezi. Ankara.(Danısman: Prof. Dr. Ömer Rıfkı Önder).

12. Aldinç H, Aytar B, Demetçi EM, Seçen, EA, Şahin A, Yllmaz H. (2004). Ankara ilinden seçilen birinci basamak sağlk kuruluşlarına başvuran 18 yaș ve üzeri kişilerin medikososyal özelliklerine göre yaşam kalitelerinin karşılaștırllması. Gazi Üniversitesi Tip Fakültesi Halk Sağlı̆̆ı AD, Ankara.

13. Arslantaş D, Metintaş S, Ünsal A, Kalyoncu C. Eskişehir Mahmudiye ilçesi yaşlllarında yaşam kalitesi. Osmangazi Tip Dergisi. 2006;28(2):81-89.

14. Tekkanat Ç. (2008). Öğretmenlik bölümünde okuyan öğrencilerde yașam kalitesi ve fiziksel aktivite düzeyleri. Yayınlanmamışyüksek lisans tezi.PAU Sağlk Bilimleri Enstitüsü, Denizli. (Danıșman: Yard. Doç. Ö. Mülazımoğlu Balli).

15. Kuyucu M. Gençlerde Akıllı Telefon Kullanımı Ve Akıllı Telefon Bağımlilğı Sorunsall: "Akıllı Telefon (Kolik)" Universite Gençliği. Global Media Journal TR Edition. 2017;7(14):328359 .

16. Birtane M, Tuna H, Ekuklu G, Uzunca K, Akçi C, Kokino S. Edirne Huzurevi sakinlerinde yașam kalitesine etki eden etmenlerin irdelenmesi. Turk Geriatr Derg. 2000;3(4):141-145. 